\title{
EFFECT OF LOW LEVEL LASER THERAPY ON ODONTOBLAST-LIKE CELLS DERIVED FROM HUMAN BONE MARROW MESENCHYMAL STEM CELLS (INVERTED PHASE CONTRAST LIGHT MICROSCOPE AND POLYMERASE CHAIN REACTION ASSESSMENT)
}

\author{
Dina M. Hassouna *, Rania M. Hassan ${ }^{* *}$, Dahlia G. Mohamed ${ }^{* * *}$ and Mostafa E. Gheith ${ }^{* * * *}$
}

\begin{abstract}
Aim: This study was designed to evaluate the effect of low level laser therapy (LLLT) on odontoblast-like cells derived from human bone marrow mesenchymal stem cells (h-BMMSCs).

Material and Methods: 40 flasks of odontoblast-like cells were obtained from 10 samples of h-BMMSCs and divided into 2 groups; control group (A) and diode laser (GaAlAs) irradiated group (B). Each group was further subdivided into 2 subgroups, where subgroups A1, B1 and A2, B2 were examined after 3 and 14 days after odontoblastic differentiation respectively. Each group was examined by inverted phase contrast light microscope to examine cell count and viability as well as alizarin red stained (ARS) mineralized matrix. Real time- polymerase chain reaction (RT-PCR) was performed for each subgroup to detect, the amount of gene expression of dentin matrix protein 1 (DMP1) and alkaline phosphatase (ALP). The data of cell count and RT-PCR were statistically analyzed.
\end{abstract}

Results: Regarding time of examination, cell count and viability statistical results showed a non-significant increase in 3 days control and irradiated subgroups (A1 and B1) compared to their corresponding control and irradiated 14 days subgroups (A2 and B2). DMP1 gene expression statistical results were significantly increased in 14 days control and irradiated subgroups (A2 and B2) than 3 days subgroups (A1 and B1). ALP gene expression results in the control subgroup at 14 days (A2) were significantly decreased than at 3 days in control (A1) subgroups and significantly increased in irradiated at 14 days (B2) than at 3 days (B1) subgroups. ARS results showed more calcific deposits in 14 days control and irradiated subgroups (A2 and B2). Regarding to irradiation, there was non-significant increase in cell count and viability results in irradiated subgroups at 3 and 14 days (B1 and B2) in comparison to their controls (A1 and A2). DMP1 and ALP gene expression results were increased significantly in irradiated subgroups (B2 and B1) than their controls (A2 and A1) respectively. ARS sections showed increased calcific deposits in irradiated subgroups (B2 and B1) in comparison to their controls (A2 and A1).

Conclusion: LLLT enhanced DMP1 and ALP gene expression, cell proliferation and matrix mineralization in odontoblast-like cells derived from h-BMMSCs.

KEYWORDS: Odontoblast-like cells, BMMSCs, Diode laser, RT-PCR, DMP1, ALP.

\footnotetext{
* Lecturer Assistant, Oral Biology Department, Fayoum University

** Associate Professor of Oral Biology, Faculty of Dentistry, Ain-Shams University

*** Lecturer of Oral Biology, Faculty of Dentistry, Ain-Shams University,

**** Professor of Laser Applications in Dental surgeries, National Institute of Laser Enhanced Sciences, Cairo University
} 


\section{INTRODUCTION}

Low level laser therapy (LLLT) plays important role in biostimulatory effect on tissues and cells such as pulpal analgesia, activation of neutrophils and macrophages which aids in the immune response and repair of the dentine-pulp complex. This occurs through odontoblasts proliferation, differentiation, and mineralization enhancing dentinogenesis either in vivo (Bjordal et al., 2006) or in vitro (Oliveira $\boldsymbol{e t}$ al., 2011). The deposition of dentin may reduce the dentin permeability to prevent or even eliminate the dentin sensitivity (Ferreira et al., 2006; Oliveira et al., 2010; Oliveira et al., 2011 and Pereira et al., 2012).

The rationale for the use of odontoblast-like cell lineages was developed since in vivo studies proved the difficulty of understanding the molecular mechanisms of odontoblast differentiation because of the close proximity of cells in varying stages of differentiation (Ruch et al.,1995; Lesot et al.,2001). It was stated that under physiological conditions, these cells synthesize dentin matrix protein and proteins associated to alkaline phosphatase (ALP) activity which are involved in dentin synthesis (Oliveira et al., 2008). Previous studies reported that odontoblast like-cells could be obtained from mesenchymal stem cells either from dental pulp or other non-dental tissues such as bone marrow (Hui et al., 2005; Abbas et al., 2013; Lei et al., 2013).

However, still remains unclear the action of low level laser therapy on odontoblast-like cells (Oliveira et al., 2011). This study was designed to determine the effect of single dose of LLLT with newly suggested parameters on odontoblast-like cell derived from h-BMMSCs.

\section{MATERIALS AND METHODS}

Ten h-BMMSCs samples of age above 18 years were collected from the clinical pathology laboratories leftover after obtaining patient consent and acceptance from Research Ethics Committee-
Faculty of Dentistry-Ain Shams University. BMMSCs were isolated and purified using Ficoll density gradient separation technique (Freshney et al., 2007). BMMSCs cell count and viability were done by hemacytometer after being stained by trypan blue and examined by inverted phase contrast light microscope (data were not shown) (De Ugarte et al., 2003). This procedure is essential for checking cell viability.

Cells were cultured in a maintenance medium $1 \mathrm{ml}$ solution in each flask consisting of Minimum Essential Medium (MEM), containing 10\% Fetal Calf Serum (FCS), 1\% antibiotics (Gentamycin) and $1 \%$ L-glutamine. Media containing cells was changed after 2 hours. When cells reached to 80$90 \%$ confluency in flasks, cells were splitted into 2 flasks. Cells were subcultured once every 3 days using trypsin/EDTA solution in order to free the cells attached to the surface. They were maintained at $37^{\circ} \mathrm{C}$ in a humidified $5 \% \mathrm{CO}_{2}$ incubator until obtaining 40 flasks of BMMSCs (Gronthos et al., 2000 and Lin et al., 2011).

In this study odontoblastic differentiation from BMMSCs was done following the same protocol of odontoblastic differentiation from dental pulp stem cells as Magne et al., 2004. On day 6 from the beginning of culturing; MEM was switched to $\alpha$-MEM and $3 \mathrm{mM}$ inorganic phosphate $(\mathrm{Pi})$ were added to the culture medium obtained from previously isolated BMMSCs. Pi was added as a mixture of $\mathrm{NaH}_{2} \mathrm{PO}_{4}$ and $\mathrm{Na}_{2} \mathrm{HPO}_{4}(\mathrm{pH}$ 7.3). Cells were treated with $100 \mathrm{ng} / \mathrm{ml}$ BMP-4 and $10 \mathrm{ng} / \mathrm{ml}$ TGF- $\beta 1$ from the $6^{\text {th }}$ to the $21^{\text {st }}$ day and media was replaced every 3 days.

BMMSCs were then tested for differentiation into odontoblast-like cells at day 21 by RT-PCR test to detect gene expression of DMP-1 and ALP and Dentin Sialophosphoprotein (DSPP) (Simon $\boldsymbol{e t}$ al., 2009; Joshi et al., 2010) after taking an aspirate from each flask. 
After confirmation of odontoblastic differentiation, the 40 samples were divided into two main groups (20 flasks each): control group A left non irradiated and irradiated group B. Odontoblastlike cells of group B were irradiated by single dose of Low Level Laser with the following parameters: Diode laser (GaAlAs), 940nm Wave length with 0.9 W (Power), continuous wave, non-contact mode for 15 seconds and $13.5 \mathrm{j}$ (Energy delivered). Then both groups A and B were subdivided into 2 subgroups (10 flasks each): A1, A2 and B1, B2 respectively. Where, subgroups A1, B1 and subgroups A2, B2 were examined 3 and 14 days respectively after odontoblastic differentiation.

Each subgroup was examined by Inverted Phase Contrast Light Microscope to detect cell count, viability after being stained with trypan blue within hemocytometer (De Ugarte et al., 2003). RT-PCR was performed for each subgroup to detect the amount of gene expression of DMP-1 and ALP (Simon et al., 2009; Joshi et al., 2010; Abbas et al., 2013).

The primers sequences of DSPP (DSPP F: 5' CAACCATAG AGAAAGCAAACGCG3', DSPPR: 5' TTTCTGTTGCCACTGCTGGGAC 3'), DMP1 (DMP1-F: 5' GCATCAGGTGGCCAAAGTAT 3', DMP1-R: 5' GAAATCCCATGCAACGTTCT 3'), ALP (ALP F: 5' CACTGCGGA CCATTCCCACGTCTT 3', ALP R: 5' GCGCCTGGTAGTTGTTGTGAG CATA 3') and GAPDH (Glyceraldehyde3-phosphate dehydrogenase) (GAPDH F:

5' ATCTTCCAGGAGCGAGATCC 3', GAPDH R: 5' ACCACTGACACGTTGGCAGT 3') were designed according to the following references (Matsui et al., 2008; Simon et al., 2009; Joshi et al., 2010; Alleman et al., 2013). Where GAPDH is a reference gene which ensures proper reactions of the RT-PCR test (Alleman et al., 2013).

Matrix mineralization was then examined by Inverted Phase Contrast Light Microscope after being stained by alizarin red stain (ARS) for further confirmation of matrix mineralization, where calcific deposits were stained red (Semeghini et al., 2012).

The data of cell count and RT-PCR were statistically analyzed using Kolmogorov-Smirnov, Shapiro-Wilk tests, Independent sample-t test and Pair-wise t-test. Statistical analysis was performed with IBM ${ }^{\circledR}$ SPSS ${ }^{\circledR}$ Statistics Version 20 for Windows.

\section{RESULTS:}

Confirmation of odontoblastic differentiation from BMMSCs was revealed by obtaining DMP1, DSPP and ALP positive results as these genes were expressed with high amounts (equivalent to 19544, 66736 and 402127 respectively) at day 21 from the beginning of cell culturing. Where DSPP gene expression indicates complete odontoblastic differentiation. GAPDH positive results was obtained equivalent to 378178.4 indicating the validity of RT-PCR test.

Cell count and viability statistical results of the present study showed that the control subgroup A1 (3 days) was significantly higher than control subgroup A2 (14 days) with statistical significance. However, irradiated subgroup B1 (3 days) showed statistical non-significant higher cell count than irradiated subgroup B2 (14 days). Both irradiated subgroups (B1 and B2) showed non-significant increase in cell count measurements compared to their control subgroups (A1 and A2) respectively, with the highest mean in 3 days after LLLT subgroup (B1) (Table 1 and Fig.1).

In the present study, DMP1 gene expression statistical results in control subgroups showed a statistically significant increased expression at 14 days (A2) compared to 3 days (A1) subgroups after odontoblastic differentiation. In LLLT group, DMP1 was expressed with statistically significant increase at 14 days (B2) than 3 days (B1) subgroups after odontoblastic differentiation. The LLLT 
irradiated group showed significant increase in DMP1 expression in comparison to their control groups with the highest mean in 14 days after LLLT subgroup (B2) (Table 2 and Fig.2).

In the present study, ALP gene expression statistical results in control subgroups showed a statistically significant increased expression at 3 days (A1) compared to 14 days (A2) subgroups after odontoblastic differentiation. In LLLT group, ALP was expressed with statistically significant increase at 14 days (B2) than 3 days (B1) subgroups after odontoblastic differentiation. The LLLT irradiated group showed significant increase in ALP expression in comparison to their control groups with the highest mean in 14 days after LLLT subgroup (B2) (Table 3 and Fig.3).

TABLE (1): The mean, standard deviation (SD) values of Cell Count and viability in subgroups A1, A2, B1 and B2.

\begin{tabular}{|c|c|c|c|c|c|}
\hline \multirow{2}{*}{ Variables } & \multicolumn{2}{|c|}{ Control (A) } & \multicolumn{2}{|c|}{ Laser (B) } & \multirow{2}{*}{ P-value } \\
\hline & subgroup & Mean \pm SD & subgroup & Mean \pm SD & \\
\hline 3Days & A1 & $434000.00 \pm 11401.75^{\mathrm{a}}$ & B1 & $446000.00 \pm 58137.76^{a}$ & $0.6 \mathrm{~ns}$ \\
\hline 14Days & A2 & $358000.00 \pm 55856.96^{b}$ & B2 & $420000.00 \pm 54313.90^{a}$ & $0.1 \mathrm{~ns}$ \\
\hline P-value & & $0.03 *$ & & $0.5 n s$ & \\
\hline
\end{tabular}

Mean with different letters in the same column indicate statistically significance difference *; significant $(p<0.05)$ ns; non-significant ( $p>0.05)$

TABLE (2): The mean, standard deviation (SD) values of DMP1 in subgroups A1, A2, B1 and B2.

\begin{tabular}{|c|c|c|c|c|c|}
\hline \multirow{2}{*}{ Variables } & \multicolumn{2}{|r|}{ Control (A) } & \multicolumn{2}{|r|}{ Laser (B) } & \multirow{2}{*}{ P-value } \\
\hline & Subgroup & Mean \pm SD & Subgroup & Mean \pm SD & \\
\hline 3 Days & $\mathrm{A} 1$ & $66696.50 \pm 1040.57^{b}$ & B1 & $70416.66 \pm 995.00^{\mathrm{b}}$ & $0.01 *$ \\
\hline 14 Days & $\mathrm{A} 2$ & $85319.23 \pm 1005.00^{c}$ & B2 & $127160.36 \pm 9995.00^{c}$ & $0.002 *$ \\
\hline P-value & & $0.001^{*}$ & & $0.001 *$ & \\
\hline
\end{tabular}

Mean with different letters in the same column indicate statistically significance difference *; significant $(p<0.05)$ ns; non-significant ( $p>0.05)$ 
TABLE (3): The mean, standard deviation (SD) values of ALP in subgroups A1, A2, B1 and B2.

\begin{tabular}{|c|c|c|c|c|c|}
\hline \multirow{2}{*}{ Variables } & \multicolumn{2}{|c|}{ Control (A) } & \multicolumn{2}{c|}{ Laser (B) } & \multirow{2}{*}{ P-value } \\
\cline { 2 - 5 } & Subgroup & Mean \pm SD & Subgroup & Mean \pm SD \\
\hline 3 Days & A1 & $215945.00 \pm 10995.00^{\mathrm{b}}$ & A1 & $1321376.80 \pm 100025.00^{\mathrm{b}}$ & $\mathbf{0 . 0 0 1 *}$ \\
\hline 14Days & A2 & $151728.83 \pm 10010.00^{\mathrm{c}}$ & $\mathbf{A 2}$ & $1373073.50 \pm 100003.50^{\mathrm{b}}$ & $\mathbf{0 . 0 0 1 *}$ \\
\hline P-value & & $\mathbf{0 . 0 3}^{*}$ & & $\mathbf{0 . 0 4 *}$ & \\
\hline
\end{tabular}

Mean with different letters in the same column indicate statistically significance difference *; significant $(p<0.05)$ ns; non-significant ( $p>0.05)$

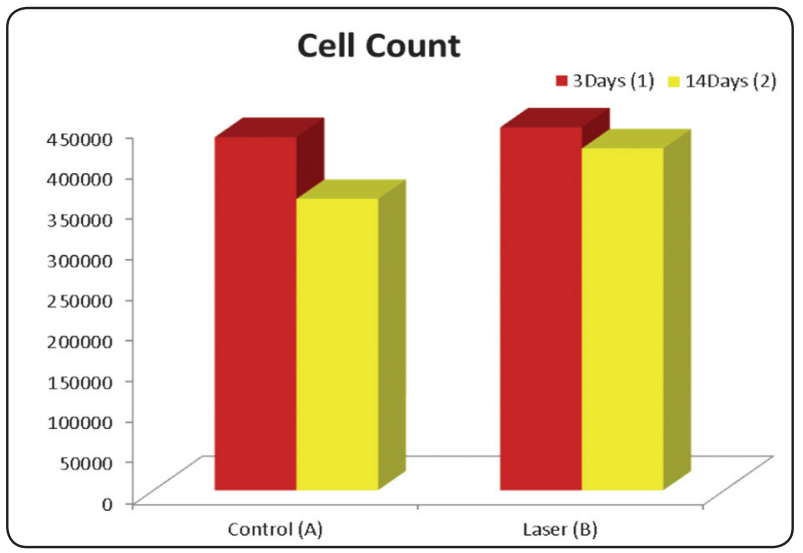

Fig. (1): Bar chart representing means of groups of Cell Count (A1,B1) 3 days and (A2,B2) 14 days.

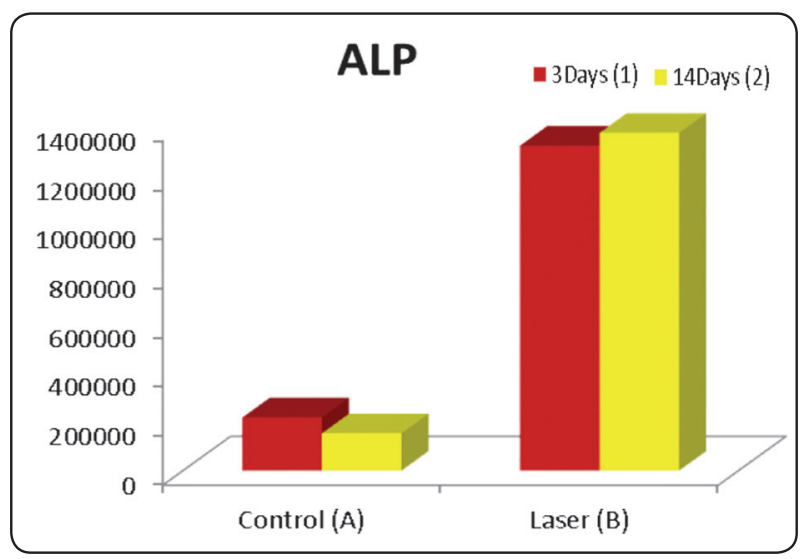

Fig. (3): Bar chart representing means of groups of ALP gene expression (A1,B1) 3 days and (A2,B2) 14 days.

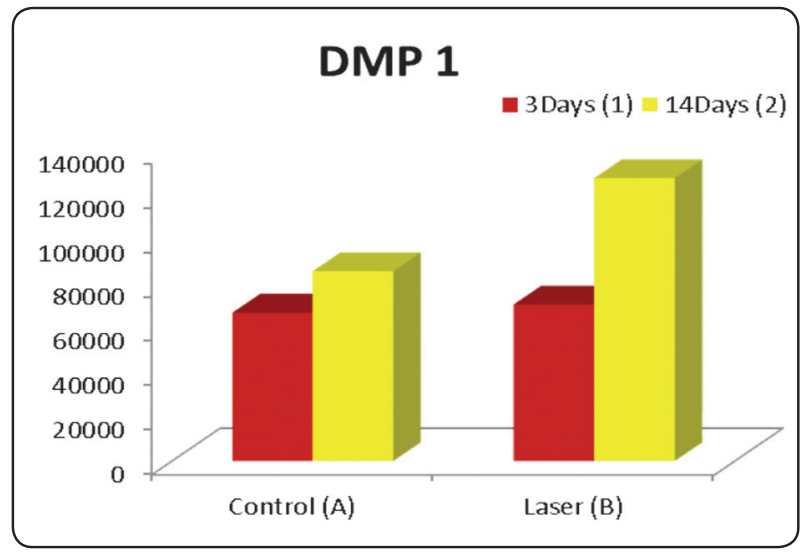

Fig. (2): Bar chart representing means of groups of DMP1 gene expression (A1,B1) 3 days and (A2,B2) 14 days.

Mineralized matrix formation by ARS results showed few meshwork-like calcific deposits at 3 days after odontoblastic differentiation in subgroup A1 (Fig. 4a). Large globules of calcific deposits were detected 14 days after odontoblastic differentiation in subgroup A2 (Fig. 4b). LLLT group showed meshwork-like calcific deposits, apparently heavier in amount and stain as well as some globules at 3 days after odontoblastic differentiation in subgroup B1 (Fig. 4c). Large, deeply stained calcific area of fused globules was detected 14 days after odontoblastic differentiation in subgroup B2 (Fig. $4 d)$. 


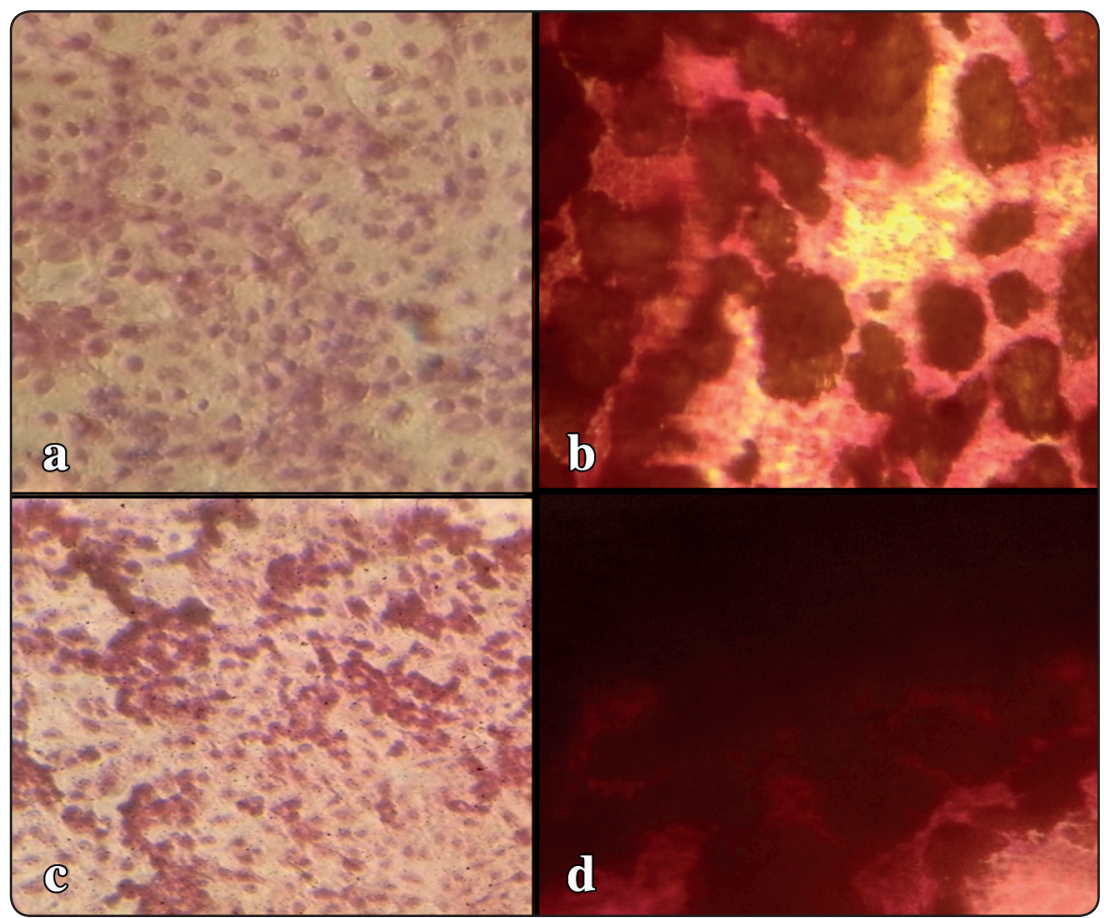

Fig. (4) Inverted Phase Contrast Light Micrograph showing few meshwork-like calcific deposits in sub group A1 (a), large globules of calcific deposits in subgroup A2 (b). Meshworklike calcific deposits, apparently heavier in amount and stain as well as some globules were detected in subgroup B1 (c) and large, deeply stained calcific area of fused globules in subgroup B2 (d). (ARS, original magnification $\mathrm{X} 100)$.

\section{DISCUSSION}

Dental stem cells of BMMSCs origin were recently presented by researchers (Li et al., 2007; Lei et al., 2013; Ishizaka et al., 2012; Ravindran and George, 2015). In the present study, odontoblast-like cells derived from BMMSCs were introduced. BMMSCs were reported to be better source of odontoblast-like cells than dental pulp mesenchymal stem cells (DPSCs), as the latter express phenotypic changes during their expansion in number which limits their use (Patel et al., 2009).

In the present study, the protocol used to induce odontoblast-like cells from BMMSCs was based on the work of Magne et al., 2004 who used rat DPSCs cell line to introduce odontoblast-like cells. This protocol was proposed based on the similarities in gene expressions between human DPSCs and human BMMSCs suggesting that induction of odontoblast-like cells is similar in both cells (Shi $\boldsymbol{e t}$ al., 2001). Ponnaiyan and Jegadeesan, 2014 also postulated that BMMSCs shares a similar pattern of protein expression with DPSCs in vitro.

In previous studies, odontoblast-like cells were induced from BMMSCs after being co-cultured with oral epithelial cells derived from rat embryos (Li $\boldsymbol{e t}$ al., 2007), or under the morphogenetic influence of dentine matrix (Lei et al., 2013). So to the best of our knowledge, this is the first time to the induce odontoblast-like cells from h-BMMSCs using Magne et al., 2004 protocol who differentiated odontoblast-like cells from rat pulpal mesenchymal stem cells.

Verification of odontoblastic differentiation from BMMSCs upon using the newly developed protocol in the present study was obtained by DMP1, ALP and DSPP gene expression positive results. The positive verification results of the present study coincided with Magne et al., 2004 and Abbas et al., 2013, who defined DSPP as a more specific gene indicating complete odontoblastic differentiation. However, it was reported that low levels of DSPP have been detected in the bones by RT-PCR (Qin et al., 2004; Nanci, 2008; Bleicher, 
2014). But Goldberg, 2014 clarified that high level of DSPP expression is specific to odontoblastic differentiation. This interpretation confirms DSPP gene expression results of this study.

In the current study, cell count and viability results regarding time, were increased after 3 days of odontoblastic differentiation subgroups (A1, B1) than after 14 days of odontoblastic differentiation subgroups (A2, B2) in both control and irradiated subgroups. This increase was statistically significant in control subgroup (A1) but statistically insignificant in irradiated subgroup (B1). This indicates that cell count and viability of the present study was more at early differentiation than at latter stages. Our results coincides with those of Semeghini et al., 2012 and Pereira et al.; 2012. The decrease in cell count at day 14 (A2) might be correlated to the reduction of cell growth after odontoblastic differentiation (Nakasone et al., 2006).

Regarding to LLLT, there was non-significant increase in cell count and viability results at 3 days (B1) than its control (A1) which coincides with the results of Oliveira et al., 2008 and Oliveira et al., 2011 upon using a lower energy dose. However, the results of the present study were not coincident with the studies of Yasuda $\boldsymbol{e t}$ al., 2009; Oliveira $\boldsymbol{e t}$ al., 2011 and De Almieda et al., 2015, where cell count and viability was significantly decreased at early differentiation after LLL irradiation when the odontoblast-like cells were irradiated with higher exposure time and energy dose. This indicated that the parameters used in this study were safe regarding odontoblastic cytotoxicity.

Statistical results of DMP1 gene expression results of the present study regarding time of examination were increased after 14 days of odontoblastic differentiation which coincides with the studies of Lacerda-Pinheiro et al., 2012; Semeghini et al., 2012 and Han et al., 2014. The previous investigators suggest that DMP1 expression occurs at later stages of dentinogenesis.
It was also reported that DMP1 plays a role in biomineralization, regulation of phosphate homeostasis and cell differentiation and is present extracellularly around the mineralizing globules (Orsini et al., 2012; Tjäderhane and Haapasalo, 2012; Goldberg, 2014) which explains the increased expression of DMP1 at 14 days after odontoblastic differentiation in the present study.

Regarding to LLLT, DMP1 gene expression statistical results showed a statistically significant increase after irradiation at 3 and 14 days after differentiation (B1 and B2) compared to their control subgroups (A1 and A2). These results coincide with those of Pereira et al., 2012 and Turrioni et al., 2014 and support the postulation of LLLT biostimulatory role on odontoblast-like cells enhancing dentinogenesis (Bjordal et al., 2006; Oliveira et al., 2011). On the other hand, our results didn't coincide with the decrease of DMP1 gene expression in the study of Pereira et al.; 2012 and De Almieda et al., 2015. Their findings could be attributed to that increasing energy density or using inadequate parameters were insufficient to biostimulate odontoblast-like cells. Furthermore, it was concluded by several studies (Huang $\boldsymbol{e t}$ al., 2009; Turrioni et al., 2014; Emelyanov and Kiryanova, 2015) that when excessive energy was applied, biostimulation was replaced by bioinhibition.

Statistical results of ALP gene expression results of the present study were decreased at day 14 from odontoblastic differentiation in control subgroups which is parallel to the results of Yokose $\boldsymbol{e t}$ al., 2000; Magne et al., 2004; Matsui et al., 2008 and Han et al., 2014. These results could be explained based on the study of Nakasone et al., 2006 who reported that the increase in ALP activity at early odontoblastic differentiation is attributed to its property to be one of the markers of odontoblastic differentiation and that ALP expression is decreased at later stages when mineralization become advanced. Our result was 
not coincided with Semeghini et al., 2012 where ALP gene expression was increased by increasing duration after odontoblastic differentiation. The investigators correlated the late increase in ALP expression to the increase in extracellular matrix mineralization globules at latter stages.

In the present study, ALP gene expression was statistically increased after LLLT at 3 and 14 days subgroups (B1 and B2) than their controls (A1 and A2). It was also found that ALP at 14 days (B2) subgroup was statistically higher than 3 days after irradiation (B1). The previous results coincide with the studies of Matsui et al., 2008; Oliveira et al., 2010; Pereira et al.; 2012 and Turrioni et al., 2014 upon using different parameters. The authors attributed increased ALP gene expression to the effect of LLLT on cell modulation responses by acting on the mitochondria increasing the levels of ATP, ALP and intracellular calcium (Karu et al., 2004; Oliveira et al., 2010; Lima et al., 2014).

Meanwhile, the increase in ALP expression in irradiated group of the present study was not coinciding with the results of Coombe et al., 2001; Khadra et al., 2005; Oliveira et al., 2008; De Almieda et al., 2015 who reported that LLLT did not influence ALP activity in cultured odontoblastlike cells. This difference in ALP results could be explained based on studies reporting that absence of ALP activity or its decrease is based on the use of LLLT parameters which could be below the minimal dose necessary to initiate biostimulation (Tuby et al., 2007; Oliveira et al., 2008; Huang et al., 2009; Emelyanov and Kiryanova, 2015).

Mineralized matrix formation stained by Alizarin Red was more advanced at 14 days after odontoblastic differentiation than at 3 days in both control and LLLT subgroups which coincides with the results of Mohamed et al., 2010 and Semeghini et al., 2012. This result was also found to confirm the increase of DMP1 level found in this study at latter stages of differentiation since DMP1 plays a vital role in biomineralization (Orsini et al., 2012; Tjäderhane and Haapasalo, 2012). Meanwhile, matrix mineralization results of control subgroups confirm the decreased ALP gene expression detected in this study at 14 days after odontoblastic differentiation (A2), as it was reported that ALP level decreases when mineralization becomes advanced at latter stages of differentiation (Yokose et al., 2000; Magne et al., 2004; Matsui et al., 2008 and Han et al., 2014).

Mineralized matrix formation results of the present study were increased after irradiation. This was in accordance with Yasuda et al., 2009, Pereira et al.; 2012. The mineralized matrix results of both irradiated subgroups (B1 and B2) confirm increased levels of DMP1 and ALP of irradiated subgroups (B1 and B2) in the present study. Where the increased DMP1 and ALP gene expression could be correlated firstly to the increase of extracellular matrix mineralization globules at latter stages of differentiation and secondly to the LLLT biostimulatory effect on mineralization (Bjordal $\boldsymbol{e t}$ al., 2006; Oliveira et al., 2011; Semeghini et al., 2012; Pereira et al.; 2012; Turrioni et al., 2014).

In the current study, the increased degree of matrix mineralizion after laser irradiation in subgroups (B1 and B2) in the present were not coincident with the results of Yasuda et al., 2009. The previous authors reported that after laser irradiation, the degree of matrix mineralization was decreased at latter stages of odontoblastic differentiation which is attributed to the use of insufficient dose to initiate biostimulation and thus biomineralization (Huang et al., 2009; Emelyanov and Kiryanova, 2015).

\section{CONCLUSIONS}

- In the present study, for the first time to our knowledge, odontoblast-like cells were derived from BMMSCs using the proposed protocol.

- Whether subjected to LLLT or not, odontoblastlike cell count was higher at early stages (3 days) of differentiation than at latter 
differentiation stages (14 days). However, DMP1 gene expression results and mineralized matrix formation increased at latter stages of differentiation.

- In control subgroups ALP gene expression was higher at the beginning of odontoblastic differentiation than at latter stages. However, in LLLT subgroups, it increased at latter stages of odontoblastic differentiation.

- LLLTenhancedDMP1 and ALPgene expression, cell proliferation and Matrix Mineralization.

\section{REFERENCES}

- $\quad$ Abbas FM, Fallahi HS, Khoshzaban A, Mahdavi N and Bagheri SS (2013). Expression of odontogenic genes in human bone marrow mesenchymal stem cells. Cell Journal 15(2): 136-141.

- Bjordal JM, Johnson MI, Iversen V, Aimbire F and LopesMartins RA (2006). Low-level laser therapy in acute pain: a systematic review of possible mechanisms of action and clinical effects in randomized placebo-controlled trials. Photomedicine and laser surgery 24: 158-68.

- Bleicher F (2014). Odontoblast physiology. Experimental cell research 325: 65-71.

- Coombe AR, Ho CT, Darendeliler MA, Hunter N, Philips JR, Chapple CC and Yum LW (2001). The effects of low level laser irradiation on osteoblastic cells. Clinical orthodontics and research 4: 3-14.

- De Almeida LF, Basso FG, Turrioni AP, de-SouzaCosta CA and Hebling J (2015). Metabolic activity of odontoblast-like cells irradiated with blue LED (455 nm). Lasers in medical science.

- De Ugarte DA, Alfonso Z, Zuk PA, Elbarbary A, Zhu M, Ashjian P, Benhaim P, Hedrick MH and Fraser JK (2003). Differential expression of stem cell mobilizationassociated molecules on multi-lineage cells from adipose tissue and bone marrow. Immunology letters 89: 267-70.

- Emelyanov AN and Kiryanova VV (2015). Photomodulation of proliferation and differentiation of stem cells by the visible and infrared light. Photomedicine and laser surgery 33: 164-74.
- Ferreira AN, Silveira L, Genovese WJ, de Araujo VC, Frigo L, de Mesquita RA and Guedes E (2006). Effect of GaAIAs laser on reactional dentinogenesis induction in human teeth. Photomedicine and laser surgery 24: 358-65.

- Freshney RI (2007). ZD6474 reverses multidrug resistance by directly inhibiting the function of P-glycoprotein. British journal of cancer 97: 1714.

- Goldberg M (2014). The Dental Pulp Biology, Pathology, and Regenerative Therapies. Springer. Berlin, Heidelberg.

- Gronthos S, Mankani M, Brahim J, Robey PG and Shi S (2000). Postnatal human dental pulp stem cells (DPSCs) in vitro and in vivo. Proceedings of the National Academy of Sciences of the United States of America 97: 13625-30.

- Han N, Zheng Y, Li R, Li X, Zhou M, Zhou M, Niu Y and Zhang Q (2014). b-Catenin Enhances Odontoblastic Differentiation of Dental Pulp Cells through Activation of Runx2. PLoSONE 9(2): e88890.

- Huang GT, Gronthos S, Shi S (2009). Mesenchymal stem cells derived from dental tissues vs. those from other sources: their biology and role in regenerative medicine. $\mathrm{J}$ Dent Res 88(9): 792-806.

- Hui JH, Ouyang HW, Hutmacher DW, Goh JC and Lee EH (2005). Mesenchymal stem cells in musculoskelet al tissue engineering: a review of recent advances in National University of Singapore. Ann Acad Med Singapore 34(2): 206-212.

- Ishizaka R, Iohara K, Murakami M, Fukuta O and Nakashima M (2012). Regeneration of dental pulp following pulpectomy by fractionated stem/progenitor cells from bone marrow and adipose tissue. Biomaterials 33: 2109-2118.

- Joshi R, Tawfik A, Edeh N, McCloud V, Looney S, Lewis J, Hsu S and Ogbureke KUE (2010). Dentin Sialophosphoprotein (DSPP) Gene-Silencing Inhibits Key Tumorigenic Activities in Human Oral Cancer Cell Line, OSC2. PLoS ONE 5(11): e13974.

- $\quad$ Karu TI, Pyatibrat LV and Afanasyeva NI (2004). A novel mitochondrial signaling pathway activated by visible-tonear infrared radiation. Photochem. Photobiol 80: 366-372.

- Khadra M, Lyngstadaas SP, Haanaes HR and Mustafa K (2005). Determining optimal dose of laser therapy for attachment and proliferation of human oral fibroblasts cultured on titanium implant material. Journal of biomedical materials research. Part A 73: 55-62. 
- Lacerda-Pinheiro S, Dimitrova-Nakov S, Harichane Y, Souyri M, Petit Cocault L, Legrès L, Marchadier A, Baudry A, Ribes S, Goldberg M, Kellermann O and Poliard A (2012). Concomitant multipotent and unipotent dental pulp progenitors and their respective contribution to mineralised tissue formation. Eur Cell Mater 23:371-86.

- $\quad$ Lei G, Yu Y, Jiang Y, Wang S, Yan M, Smith AJ, Smith G, Cooper PR, Tang C, Zhang G and Yu J (2013). Differentiation of BMMSCs into odontoblast-like cells induced by natural dentine matrix. Journal Arch Oral Biol 58(7):862-70.

- Lesot H, Lisi S, Peterkova R, Peterka M, Mitolo V and Ruch JV (2001). Epigenetic signals during odontoblast differentiation. Adv Dent Res 15:8-13.

- $\quad$ Li ZY, Chen L, Liu L, Lin YF, Li SW, Tian WD (2007). Odontogenic potential of bone marrow mesenchymal stem cells. J Oral Maxillofac Surg 65: 494-500.

- $\quad$ Lima AF, Basso FG, Ribeiro APD, Bagnato VS, Hebling J, Marchi GM and de Souza Costa CA (2014). Effects of Laser Irradiation on Pulp Cells Exposed to Bleaching Agents. Photochemistry and Photobiology 90: 201-206.

- $\quad$ Lin CY, Lin HH, Chen MH (2011). Zinc Chloride for Odontogenesis of Dental Pulp Stem Cells via Met allothionein Up-regulation. JOE 37(2).

- Linde A (1989). Dentin matrix proteins: composition and possible functions in calcification. Anatomical Record 224: 154-66.

- Magne D, Bluteau G, Lopez-Cazaux S, Weiss P, Pilet P, Ritchie HH, Daculsi G and Guicheux J (2004). Development of an odontoblast in vitro model to study dentin mineralization. Connective Tissue Research 45(2): 101-8.

- $\quad$ Matsui S, Takeuchi H, Tsujimoto Y and Matsushima K (2008). Effects of Smads and BMPs induced by Ga-AlAs laser irradiation on calcification ability of human dental pulp cells. Journal of Oral Science 50(1): 75-81.

- Mohamed MS, Hakam HM and Korany NS (2010). Expression of mineralization markers in isolated postnatal human dental pulp stem cells in diabetic patients (An in vitro study). Egyptian Dental Journal 56: 1733:1740.

- Nakashima M and Reddi AH (2003). The application of bone morphogenetic proteins to dental tissue engineering. Nature Biotechnology 21(9): 1025-1032.

- Nakasone N, Yoshie H and Ohshima H (2006). An immune-histochemical study of the expression of heat- shock protein-25 and cell proliferation in the dental pulp and enamel organ during odontogenesis in rat molars. Arch Oral Biol 51:378-386.

- Nanci A (2008). Ten Cate's Oral Histology. 7th ed. St. Louis. Mosby Elsevier. Canada. pp: 191-238.

- Oliveira CF, Basso FG, Lins EC, Kurachi C, Hebling J, Bagnato VS, and de Souza Costa CA (2011). In vitro effect of low-level laser on odontoblast-like cells. Laser Physics Letter 8(2): 155-163.

- $\quad$ Oliveira CF, Basso FG, Lins EC, Kurachi C, Hebling J, Bagnato VS, and de Souza Costa CA (2011). In vitro effect of low-level laser on odontoblast-like cells. Laser Physics Letter 8(2): 155-163.

- $\quad$ Oliveira CF, Hebling J, Souza PPC, Sacono NT, Lessa FR, Lizarelli RFZ and Costa CAS (2008). Effect of low-level laser irradiation on odontoblast-like cells. Laser Phys. Lett 5(9): 680-685.

- Orsini G, Ruggeri A, Mazzoni A, Nato F, Manzoli L, Putignano A, Di Lenarda R, Tjäderhane L and Breschi L (2012). A review of the nature, role and function of dentin non-collagenous proteins. Part 1: proteoglycans and glycoproteins. Endodontic Topics 21: 1-18.

- $\quad$ Patel M, Smith AJ, Sloan AJ, Smith G and Cooper PR (2009). Phenotype and behaviour of dental pulp cells during expansion culture. Archives of Oral Biology 54(10): 898-908.

- Pereira LB, Chimello DT, Ferreira MRW, Bachmann L, Rosa AL and Bombonato-Prado KF (2012). Low-Level Laser Therapy Influences Mouse Odontoblast-Like Cell Response in Vitro. Photomedicine and Laser Surgery 30(4): 206-213.

- Ponnaiyan D and Jegadeesan V (2014). Comparison of phenotype and differentiation marker gene expression profiles in human dental pulp and bone marrow mesenchymal stem cells. European Journal of Dentistry $8(3)$.

- $\quad$ Qin C, Baba O and Butler WT (2004). Post-translational modifications of sibling proteins and their roles in osteogenesis and dentinogenesis. Crit Rev Oral Biol Med 15(3):126-36.

- Ravindran S and George A(2015). Biomimetic extracellular matrix mediated somatic stem cell differentiation: applications in dental pulp tissue regeneration. Frontiers in Physiology 6(118). 
- $\quad$ Ruch JV, Lesot H and Begue-Kirn C (1995). Odontoblast differentiation. The International journal of developmental biology 39: 51-68.

- $\quad$ Semeghini MS, Fernandes RR, Chimello DT, de Oliveira FS and Bombonato-Prado KF (2012). In Vitro Evaluation of the Odontogenic Potential of Mouse Undifferentiated Pulp Cells. Braz Dent J 23(4): 328-336.

- Shi S, Robey PG and Gronthos S (2001). Comparison of human dental pulp and bone marrow stromal stem cells by cDNA microarray analysis. Bone J 29: 532-539.

- Simon S, Berdal A and Smith AJ (2009). Molecular Characterisation of Odontoblast during Primary, Secondary and Tertiary dentinogenesis. Phd thesis. University of Birmingham. UK.

- Tjäderhane L and Haapasalo M (2012). The dentin-pulp border: a dynamic interface between hard and soft tissues. Endodontic Topics 20: 52-84.
- Tuby H, Maltz L, and Oron U (2007). Low-level laser irradiation (LLLI) promotes proliferation of mesenchymal and cardiac stem cells in culture. Lasers Surg. Med 39(4): 373-8.

- Turrioni APS, Basso FG, Montoro LA,. de Almeida LF, Costa CAS, Hebling J (2014). Phototherapy up-regulates dentin matrix proteins expression and synthesis by stem cells from human-exfoliated deciduous teeth. Journal Of Dentistry 42: 1292 - 1299 .

- $\quad$ Yasuda Y, Ohtomo E, Tsukuba T, Okamoto K and SaitoT (2009). Carbon dioxide laser irradiation stimulates mineralization in rat dental pulp cells. International Endodontic Journal 42: 940-946.

- Yokose S, Kadokura H, Tajima Y, Fujieda K, Katayama I, Matsuoka T and Katayama T (2000). Establishment and characterization of a culture system for enzymatically released rat dental pulp cells. Calcif Tissue Int 66(2): 139-144. 